\title{
Microbial aetiology, outcomes, and costs of hospitalisation for community-acquired pneumonia; an observational analysis
}

\author{
Simone MC Spoorenberg ${ }^{1 *}$, Willem Jan W Bos ${ }^{1}$, Rik Heijligenberg ${ }^{2}$, Paul GP Voorn ${ }^{3}$, Jan C Grutters ${ }^{4,5}$, Ger T Rijkers ${ }^{3,6}$
} and Ewoudt MW van de Garde

\begin{abstract}
Background: The aim of this study was to investigate the clinical outcome and especially costs of hospitalisation for community-acquired pneumonia (CAP) in relation to microbial aetiology. This knowledge is indispensable to estimate cost-effectiveness of new strategies aiming to prevent and/or improve clinical outcome of CAP.

Methods: We performed our observational analysis in a cohort of 505 patients hospitalised with confirmed CAP between 2004 and 2010. Hospital administrative databases were extracted for all resource utilisation on a patient level. Resource items were grouped in seven categories: general ward nursing, nursing on ICU, clinical chemistry laboratory tests, microbiology exams, radiology exams, medication drugs, and other.linear regression analyses were conducted to identify variables predicting costs of hospitalisation for CAP.

Results: Streptococcus pneumoniae was the most identified causative pathogen (25\%), followed by Coxiella burnetii (6\%) and Haemophilus influenzae (5\%). Overall median length of hospital stay was 8.5 days, in-hospital mortality rate was $4.8 \%$.

Total median hospital costs per patient were $€ 3,899$ (IQR 2,911-5,684). General ward nursing costs represented the largest share (57\%), followed by nursing on the intensive care unit (16\%) and diagnostic microbiological tests (9\%). In multivariate regression analysis, class IV-V Pneumonia Severity Index (indicative for severe disease), Staphylococcus aureus, or Streptococcus pneumonia as causative pathogen, were independent cost driving factors. Coxiella burnetii was a cost-limiting factor.
\end{abstract}

Conclusions: Median costs of hospitalisation for CAP are almost $€ 4,000$ per patient. Nursing costs are the main cause of these costs.. Apart from prevention, low-cost interventions aimed at reducing length of hospital stay therefore will most likely be cost-effective.

Keywords: Pneumonia, Bacterial infection, Health economist, Respiratory infection

\section{Background}

Community-acquired pneumonia (CAP) is one of the most common infectious diseases worldwide; in the developed world, CAP, combined with influenza, is the primary cause of death due to infection [1]. Incidence of CAP is high in young children, then decreases and in adults, again increases with age; consequently, CAP carries a high burden, in particular in the elderly $[2,3]$. As $20-40 \%$ of

\footnotetext{
* Correspondence: s.spoorenberg@antoniusziekenhuis.nl

'Department of Internal Medicine, St Antonius Hospital, P.O. Box 2500,

3430 EM, Nieuwegein, The Netherlands

Full list of author information is available at the end of the article
}

all CAP episodes in the elderly are treated in-hospital [4], hospital admissions for pneumonia result in considerable health care costs [2,5]. In 1997, these costs were estimated to be $€ 115$ million in Spain [6] and almost $£ 400$ million in the United Kingdom [7]. With the post Second World War generation approaching senescence and the rise of life expectancy in general, the number of hospital admissions for pneumonia and associated health care costs will continue to rise [8].

Many studies have been conducted to assess the effect of interventions with the aim of reducing the risk and improving the outcome of CAP. For instance, the introduction 
of vaccination against Influenza has reduced severity and mortality of secondary pneumonia [9], adjunctive therapies such as corticosteroids have been shown to reduce length of hospital stay [10] and some studies showed lowering of incidence and mortality of pneumococcal pneumonia in nursing home residents through use of pneumococcal vaccines [11] although others found no protective effect [12-14]. In order to determine overall cost-effectiveness of such interventions, knowledge of the association between microbial aetiology, outcomes, and costs of CAP is indispensable.

The objectives of the present study were to analyse microbial aetiology and clinical outcomes of a large cohort of patients hospitalised for CAP, to determine individual hospital resource utilization, to quantify total costs of hospitalisation for CAP and to explore possible associations between microbial aetiology and the corrsponding costs.

\section{Methods}

\section{Patients}

Patients with CAP above 18 years of age admitted to the St. Antonius Hospital in Nieuwegein or the Gelderse Vallei Hospital in Ede (both teaching hospitals in the Netherlands), between October 2004 and August 2006 $(n=201)$, and between November 2007 and September 2010 ( $n=304)$, who participated in two consecutive clinical studies were enrolled. The first study was a prospective cohort study on clinical characteristics and polymorphisms in innate immunity genes in patients with CAP; the second study was a placebo controlled double blind randomized clinical trial evaluating dexamethasone as adjunctive therapy (NCT00471640). In both studies, the same clinical inclusion criteria were used and patient characteristics of the patients studied resembled data from another large CAP cohort (over 20,000 patients admitted to hospital for pneumonia) from the same time period [15]. CAP was defined as a new pulmonary infiltrate on chest radiograph, in combination with at least two of the following criteria: cough, sputum production, temperature above $38^{\circ} \mathrm{C}$ or below $35^{\circ} \mathrm{C}$, auscultatory findings consistent with pneumonia, C-reactive protein concentration of more than $15 \mathrm{mg} / \mathrm{L}$, and white blood cell count of above $10 \times 10^{9}$ cells/L or below $4 \times 10^{9}$ cells $/ \mathrm{L}$, or $>10 \%$ of rods in leukocyte differentiation. Patients who were immunocompromised, had been directly admitted to the intensive care unit (ICU), or who had received immunosuppressive therapy (including the use of $>20 \mathrm{mg}$ prednisone equivalent per day for $>3$ days) were excluded. More detailed inclusion and exclusion criteria are described elsewhere $[10,16]$. Comorbidities were recorded of each patient and pneumonia severity index (PSI) score was calculated on admission. The present study has been approved by the Medical Ethical Committees of the St. Antonius Hospital
(Nieuwegein) and the Gelderse Vallei Hospital (Ede), both in The Netherlands.

\section{Microbial aetiology}

At least two sets of separate blood and sputum samples of each patient were Gram stained and cultured. Streptococcus (S.) pneumoniae cultured from either sputum or blood was serotyped by the Quellung reaction. Moreover, sputum samples were analysed with TaqMan real-time polymerase chain reactions (PCRs) in order to detect DNA of Mycoplasma (M.) pneumoniae, Legionella (L.) pneumophila, Coxiella (C.) burnetii, and Chlamydophila species. Antigen testing of S. pneumoniae and L. pneumophila was performed in urine samples. Furthermore, pharyngeal swabs were taken for viral culture and viral PCR. Finally, patients were analysed for a serotype specific rise in S. pneumoniae antibodies when two blood samples (one drawn at admission and one after discharge) were available. Antibodies against pneumococcal polysaccharides were measured on a Luminex platform (Luminex Corporation, Austin, TX), using a quantitative multiplex immunoassay: the xMAP pneumococcal immunity panel. More detailed information can be found elsewhere [17].

If both a bacterium and virus were detected in a patient, the bacterial species was classified as the causative pathogen. If two different bacterial species were identified, the pathogen known to most likely cause CAP was considered causative. For the purpose of this study, aetiological agents were classified into ten groups: the first seven groups consist of the most frequently identified bacteria (S. pneumoniae, C. burnetii, Haemophilus (H.) influenzae, L. pneumophila, Chlamydophila species, M. pneumoniae, and Staphylococcus aureus), group eight contains remaining bacteria ('Other pathogen'), group nine comprises viruses ('Viral pathogen'), and the last group consists of CAPs with unidentified aetiology ('No pathogen identified').

\section{Clinical outcomes}

ICU admission during hospitalisation, length of stay, in-hospital mortality, 30-day and one-year mortality were documented for each patient.

\section{Resource utilization and cost calculation}

Hospital administrative databases were extracted for all resource utilisation on a patient level. Resource items were grouped in seven categories: general ward nursing, nursing on ICU, clinical chemistry laboratory tests, microbiology exams, radiology exams, medication drugs, and other. Except for nursing, only resources plausibly related to pneumonia treatment were selected. For example, medication drug use only included antibiotics, analgesics, bronchodilators, sedatives, blood products and antithrombotic drugs. The category "other" comprised physical therapy sessions, electro and echocardiograms, bronchoscopy and 
laryngoscopy and invasive empyema diagnostic and treatment procedures. For duration of nursing, the unit of measurement was number of days.

Total costs per patient were calculated by summing the number of resources multiplied by the costs per item. Costs per resource item were based on the National Diagnosis Treatment Combination rates valued in 2011 or 2012 [18], except for nursing costs during hospital stay and costs of medication drugs. Nursing costs for general ward and ICU stay were based on mean costs per hospital unit prices belonging to diagnostic treatment combination code 401 ('pneumonia') for the year 2011. Costs of drugs were based on the lowest medication drug price according to the College for Health Insurance website valued in 2012 [19]; if not available on this website, the hospital's purchase price was recorded.

\section{Data analyses}

Overall, descriptives were stated as number (\%), mean (standard deviation (SD)) or median (interquartile range (IQR)), and compared using independent samples T-test, Chi-square test, or Mann-Whitney U test, where appropriate. Kruskall Wallis test was used to assess overall differences in length of stay and costs between aetiologic groups.

To identify variables predicting costs of hospitalisation for CAP, linear regression analyses were conducted with $\log$-transformed data. Costs were log-transformed to correct for skewness of the data. First, the following variables were examined in a univariate model (with reference group): male gender (female), chronic obstructive pulmonary disease (no chronic obstructive pulmonary disease), congestive heart failure (no congestive heart failure), diabetes mellitus (no diabetes mellitus), PSI classes IV-V (classes I-III), and admission in 'Gelderse Vallei Hospital' (St. Antonius Hospital). The ten aetiologic groups were included separately in the model; reference value per group was composed of the other nine aetiologic groups. Subsequently, variables significant in univariate models $(\mathrm{p}<0.10)$ were inserted in a multivariate model, applying a backwards elimination technique retaining variables with a p-value $<0.10$. For the final model, effects (costs) were stated as beta with corresponding standard error for each independent variable. Data were analysed with SPSS statistical software for Windows, version 21.0. For all analyses, a $\mathrm{p}$-value of $<0.05$ was considered statistically significant.

\section{Results}

A total of 505 patients with CAP were subject in this study, with a mean age of $63.4 \pm 18.0$ years and a male/ female ratio of 1.4/1. Patient characteristics are presented in Table 1.
Table 1 Characteristics of $\mathbf{5 0 5}$ patients hospitalised with community-acquired pneumonia

\begin{tabular}{ll}
\hline Characteristics & $\begin{array}{l}\text { All patients } \\
(\boldsymbol{n}=505)\end{array}$ \\
\hline Age in years (SD) & $63.4(18.0)$ \\
Male sex (\%) & $295(58.4)$ \\
Comorbidities (\%) & \\
Chronic obstructive pulmonary disease & $98(19.4)$ \\
Congestive heart failure & $68(13.5)$ \\
Renal disease & $40(7.9)$ \\
Diabetes mellitus & $77(15.2)$ \\
Liver disease & $2(0.4)$ \\
Pneumonia Severity Index class I-III (\%) & $279(55.2)$ \\
Pneumonia Severity Index class IV-V (\%) & $226(44.8)$ \\
Pathogens (\%) & \\
Streptococcus pneumoniae & $124(24.6)$ \\
Coxiella burnetii & $28(5.5)$ \\
Haemophilus influenzae & $27(5.3)$ \\
Legionella pneumophila & $20(4.0)$ \\
Chlamydophila species & $16(3.2)$ \\
Mycoplasma pneumoniae & $9(1.8)$ \\
Staphylococcus aureus & $9(1.8)$ \\
Only viral pathogen & $35(6.9)$ \\
Other pathogen & $27(5.3)$ \\
No pathogen identified & $210(41.6)$
\end{tabular}

Empirical antibiotic treatment (\%)

Beta-lactam, penicillins (monotherapy) 254 (50.3)

Other beta-lactam (monotherapy) $86(17.0)$

Beta-lactam, penicillins + quinolone $34(6.7)$

Beta-lactam, penicillins + macrolides $33(6.5)$

Other beta-lactam + aminoglycoside $20(4.0)$

Other beta-lactam + quinolone 16 (3.2)

Quinolone (monotherapy) 11 (2.2)

Macrolides, lincosamides and streptogramins (monotherapy) 11 (2.2)

Beta-lactam, penicillin + aminoglycoside 7 (1.4)

Other beta-lactam, penicillin + macrolides $\quad 7$ (1.4)

Sulfanomides and trimethoprim (monotherapy) 6 (1.2)

Tetracyclines (monotherapy) 6 (1.2)

Other $14(2.8)$

Outcomes

Length of hospital stay (IQR) 8.5 (6.0-13.0)

Intensive care unit admission (\%) 38 (7.5)

In-hospital mortality (\%) $24(4.8)$

30-Day mortality (\%) $26(5.1)$

One-year mortality (\%) $73(14.5)^{\perp}$

Data are presented as number (\%), mean (SD) or median (IQR) Abbreviations: IQR interquartile range, $S D$ standard deviation.

${ }^{\perp} 7$ patients were lost to follow-up. 
Table 2 Microbiology tests results of $\mathbf{5 0 5}$ patients hospitalised with community-acquired pneumonia

\begin{tabular}{|c|c|c|c|c|c|c|}
\hline & Sputum culture & Sputum PCR & Blood culture & Blood PCR & Urinary antigen test & Serology \\
\hline S. pneumoniae $n=124$ & 46 & - & 42 & - & 78 & 1 \\
\hline Haemophilus influenzae $\mathrm{n}=27$ & 25 & 1 & - & - & - & 1 \\
\hline Legionella pneumophila $\mathrm{n}=20$ & 1 & 3 & - & - & 15 & 6 \\
\hline Mycoplasma pneumoniae $\mathrm{n}=9$ & - & 4 & - & - & - & 7 \\
\hline Coxiella burnetii $\mathrm{n}=28$ & 1 & 12 & 2 & 12 & - & 20 \\
\hline Chlamydophila spp. $\mathrm{n}=16$ & - & 8 & - & - & - & 12 \\
\hline Staphylococcus aureus $n=9$ & 8 & - & 1 & - & - & - \\
\hline Other pathogen $n=27$ & 23 & - & 5 & - & - & - \\
\hline Viral pathogen $n=35$ & 3 & 2 & - & - & - & 19 \\
\hline
\end{tabular}

Abbreviations: $n$ number, S. pneumoniae Streptococcus pneumoniae, spp species.

\section{Aetiology and clinical outcomes}

In $294 / 505(58.2 \%)$ patients, a causative pathogen was identified. Table 2 lists the microbiological test results of most frequently identified pathogens. Overall, S. pneumoniae was most prevalent $(124 / 505,24.6 \%)$. In 51 of these 124 patients, S. pneumoniae serotyping could be performed. Type 1 was the most common serotype. A complete overview of the pneumococcal serotypes is given in Additional file 1: Table S1. In 43/505 patients a mixed infection was found. No penicillin resistant S. pneumoniae, methycillinresistant Staphylococcus aureus or multi-resistant gramnegative pathogens were identified.

Clinical outcomes categorized by aetiology group are listed in Table 3. Overall, LOS differed significantly between the major aetiological groups $(\mathrm{p}<0.001)$. CAP caused by either M. pneumoniae or C. burnetii was associated with a significantly shorter LOS compared to the other aetiologic groups (p:0.007 and $\mathrm{p}<0.001$, respectively), while $S$. pneumoniae CAPs resulted in a significantly longer duration of hospital stay (p:0.03).

\section{Hospital costs}

For $361 / 505(71.5 \%)$ of the patients complete resource utilization data were available for analysis. The clinical characteristics of the 144 patients who could not be included, as compared to the included patients can be found in Additional file 1: Table S2.

\section{Total costs}

Table 4 lists the top 10 most frequent and the top 10 most expensive resource items. In the Additional file 1, the top 5 most frequent used items for each individual category can be found in Table S3.

Figure 1 shows the total distribution of hospital costs per patient. Total median hospital costs per patient were $€ 3,899$ (IQR 2,911-5,684) with minimum costs of €901 and maximum costs of $€ 112,634$. Figure 2 shows the share per category in the total costs: general ward nursing represented the largest share (56.5\%), followed by nursing on ICU (16.4\%) and diagnostic microbiology exams (9.4\%).

Table 3 Clinical outcomes per pathogen of 505 patients hospitalised with community-acquired pneumonia

\begin{tabular}{|c|c|c|c|c|c|}
\hline & $\begin{array}{l}\text { Length of hospital } \\
\text { stay (IQR) }\end{array}$ & $\begin{array}{c}\text { ICU } \\
\text { admission (\%) }\end{array}$ & $\begin{array}{c}\text { In-hospital } \\
\text { mortality (\%) }\end{array}$ & $\begin{array}{c}\text { 30-day } \\
\text { mortality (\%) }\end{array}$ & $\begin{array}{c}\text { One-year } \\
\text { mortality (\%) }\end{array}$ \\
\hline Streptococcus pneumoniae $(n=124)$ & $8.5(6.5-14.9)$ & $10(8.1)$ & $4(3.2)$ & $4(3.2)$ & $12(9.7)$ \\
\hline Coxiella burnetii $(\mathrm{n}=28)$ & $5.5(3.5-7.5)$ & 0 & 0 & $1(3.6)$ & $1(3.6)$ \\
\hline Haemophilus Influenzae $(n=27)$ & $9.0(7.5-14.0)$ & $2(7.4)$ & 0 & 0 & $3(11.1)$ \\
\hline Legionella pneumophila $(n=20)$ & $11.0(6.5-17.0)$ & $3(15.0)$ & $1(5.0)$ & $1(5.0)$ & $2(10.0)$ \\
\hline Chlamydophila species $(n=16)$ & $8.5(6.6-13.3)$ & $2(12.5)$ & 0 & 0 & $1(6.3)$ \\
\hline Mycoplasma pneumoniae $(\mathrm{n}=9)$ & $5.0(4.5-7.3)$ & 0 & 0 & 0 & 0 \\
\hline Staphylococcus aureus $(\mathrm{n}=9)$ & $10.5(7.3-14.5)$ & $1(11.1)$ & $3(33.3)$ & $3(33.3)$ & $4(44.4)$ \\
\hline Other pathogen $(n=27)$ & $8.0(5.0-15.8)$ & $7(25.9)$ & $2(7.4)$ & $2(7.4)$ & $9(33.3)$ \\
\hline Viral pathogen $(n=35)$ & $8.5(6.3-13.5)$ & $1(2.9)$ & $2(5.7)$ & $3(8.6)$ & $6(17.1)$ \\
\hline No pathogen found $(n=210)$ & $8.5(5.5-12.6)$ & $12(5.7)$ & $12(5.7)$ & $12(5.7)$ & $35(16.7)$ \\
\hline
\end{tabular}

Data are presented as number (\%) or median (IQR). For calculation of median length of stay patients who died during admission where excluded from 
Table 4 Top 10 most frequent and top 10 most expensive resource items with prices in euro

\begin{tabular}{|c|c|c|c|}
\hline & Resource & $\begin{array}{l}\text { Mean frequency } \\
\text { per patient }\end{array}$ & $\begin{array}{l}\text { Price per } \\
\text { item (in euro) }\end{array}$ \\
\hline & $\begin{array}{l}10 \text { Most frequent resource } \\
\text { items }\end{array}$ & & \\
\hline 1 & $\begin{array}{l}\text { Tissue obtainment (microbiology } \\
\text { and clinical chemistry) }\end{array}$ & 18.1 & 13.73 \\
\hline 2 & $\begin{array}{l}\text { Antibodies against any pathogen } \\
\text { by using complement fixation test } \\
\text { of haemagglutination inhibition } \\
\text { essay }\end{array}$ & 10.4 & 4.84 \\
\hline 3 & General ward nursing (one day) & 9.4 & 375.00 \\
\hline 4 & Sodium & 8.2 & 1.76 \\
\hline 5 & Potassium & 8.2 & 1.76 \\
\hline 6 & Creatinine & 6.6 & 1.76 \\
\hline 7 & Glucose & 6.4 & 1.76 \\
\hline 8 & Leukocytes & 6.1 & 1.76 \\
\hline 9 & C-reactive protein & 6.0 & 4.84 \\
\hline \multirow[t]{2}{*}{10} & Urea & 5.9 & 1.76 \\
\hline & $\begin{array}{l}10 \text { Most expensive resource } \\
\text { items }\end{array}$ & & \\
\hline 1 & $\begin{array}{l}\text { Intensive care unit nursing } \\
\text { (one day) }\end{array}$ & 0.6 & $1,730.00$ \\
\hline 2 & $\begin{array}{l}\text { Surgical treatment of thorax } \\
\text { empyema }\end{array}$ & 0.2 & $1,084.75$ \\
\hline 3 & Laryngoscopy & 0.0 & 999.00 \\
\hline 4 & $\begin{array}{l}\text { Microbiological determination } \\
\text { on isolated DNA/RNA }\end{array}$ & 0.0 & 867.61 \\
\hline 5 & General ward nursing (one day) & 9.4 & 375.00 \\
\hline 6 & Flexible bronchoscopy & 0.2 & 209.25 \\
\hline 7 & $\begin{array}{l}\text { DNA/RNA amplification } \\
\text { (qualitative) }\end{array}$ & $<0.1$ & 208.60 \\
\hline 8 & Computer tomography of thorax & 0.2 & 195.83 \\
\hline 9 & Immunopathologic research & $<0.1$ & 109.57 \\
\hline 10 & Computer tomography airways & $<0.1$ & 160.01 \\
\hline
\end{tabular}

\section{Costs categorized per aetiological group}

Overall, total hospital costs differed between the 10 aetiological groups (p:0.002); costs for hospitalisation of CAP caused by C. burnetii were significantly lower $(\mathrm{p}<0.001)$, while hospitalisation of patients with $S$. pneumoniae as causative agent represents significantly higher costs (p:0.03) compared to other aetiologies. For $M$. pneumoniae and Staphylococcus aureus a trend towards respectively lower and higher costs (p: 0.10 and p:0.08, respectively) was observed.

Figure 3 shows median costs of each aetiologic group subdivided into the seven resource categories. Raw numbers of this figure can be found in Additional file 1: Table S4. Overall, costs for general ward nursing, microbiology exams, clinical chemistry laboratory tests, medication

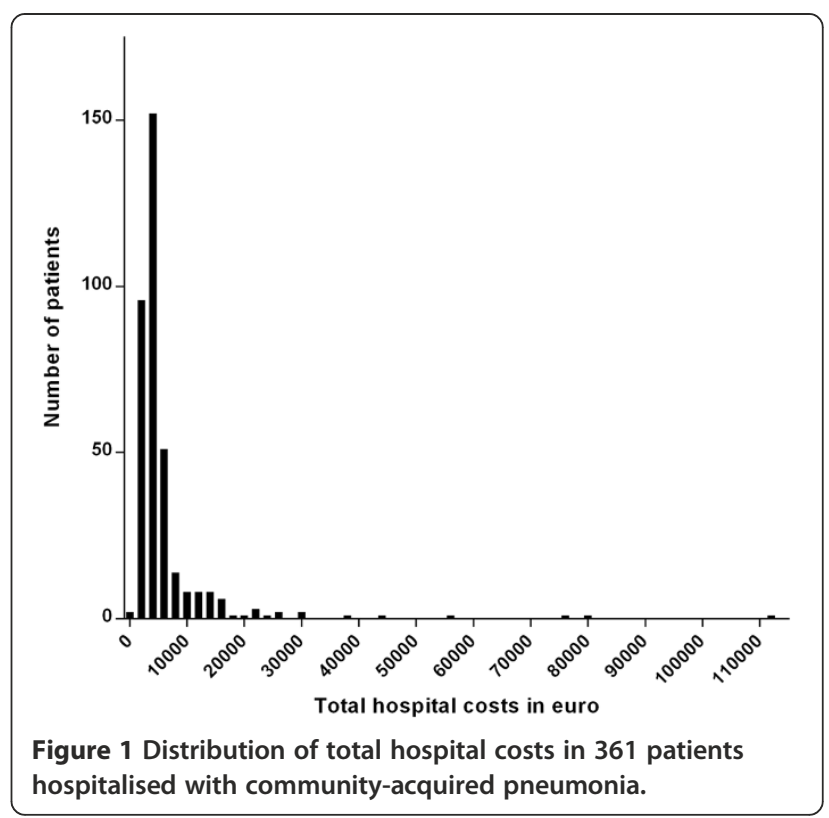

drugs, and radiologic exams all differed between the aetiological groups. On an individual pathogen level, CAP caused by C. burnetii was lower in costs for nursing, clinical chemistry tests, and radiological examinations compared to most of the other aetiological groups. Costs of medication were specifically high in patients with $L$. pneumophila pneumonia. CAP caused by Staphylococcus aureus was higher in costs for nursing and CAP caused by $S$. pneumoniae was more expensive in radiological

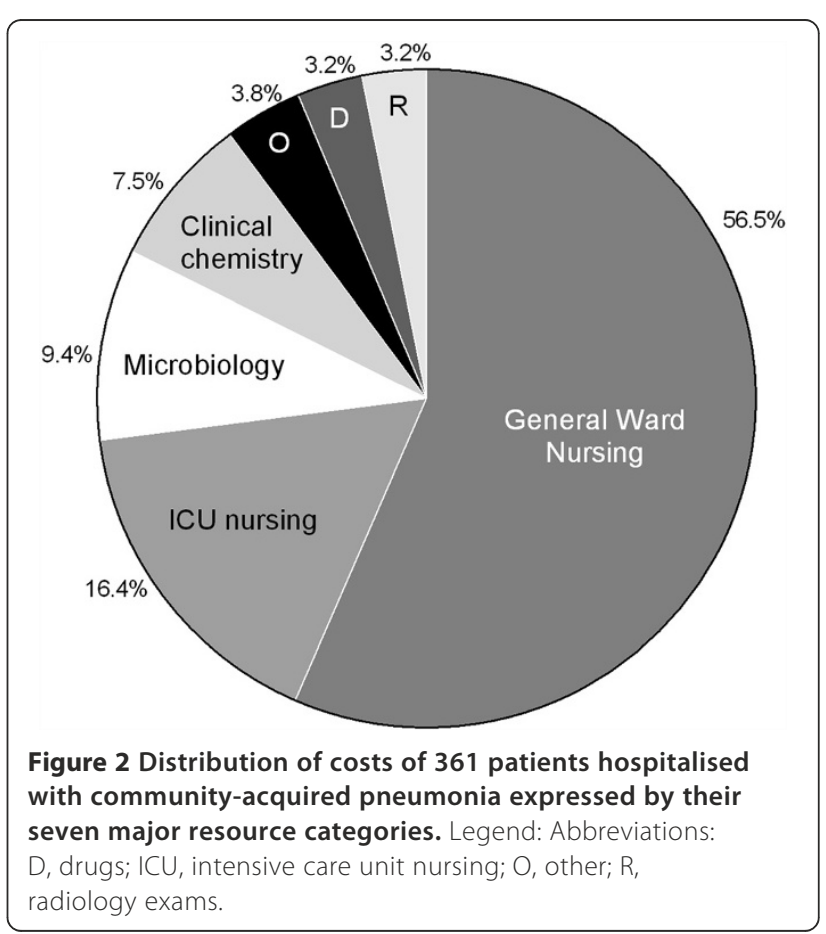




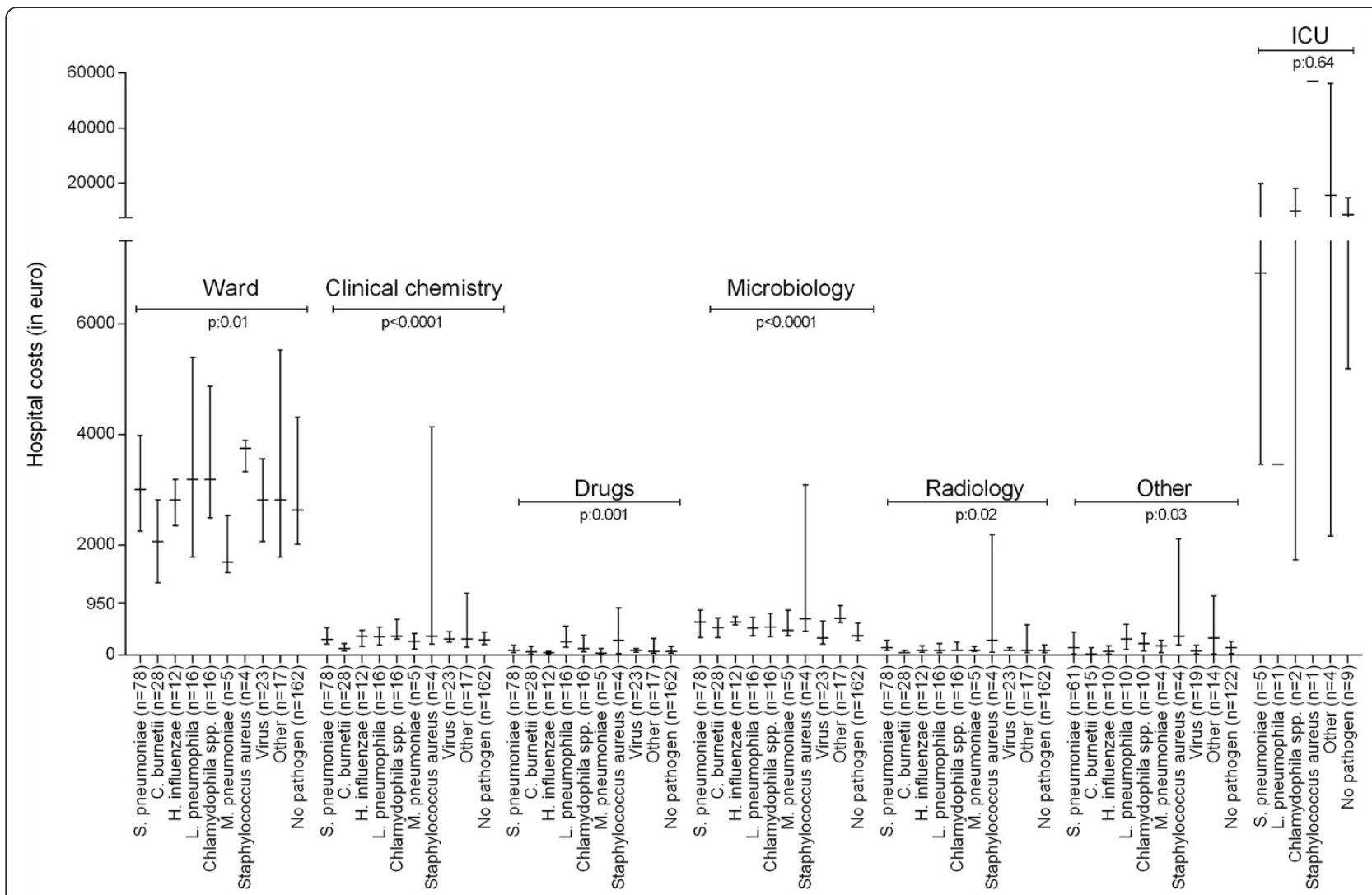

Figure 3 Median hospital costs in euro with interquartile range per aetiology differentiated by resource group. Legend: Abbreviations: $C$. burnetii, Coxiella burnetii; H. influenzae, Haemophilus influenzae; ICU, intensive care unit; L. pneumophila, Legionella pneumophila; M. pneumoniae, Mycoplasma pneumoniae; n, number; spp, species; S. pneumoniae, Streptococcus pneumoniae.

examinations. Additional file 1: Table S5A to S5G shows details of this aetiological subgroup analysis.

\section{Costs per S. pneumoniae serotype}

As $S$. pneumoniae is the most frequent identified pathogen in CAP, costs of serotypes were explored grouped per pneumococcal vaccine available in the European Union (results presented in Additional file 1: Table S6). Total costs of hospitalisation were not higher for patients with CAP caused by the serotypes present in the different vaccines compared to patients infected by pneumococcal serotypes not included in these vaccines.

\section{Identification of cost driving factors}

To identify cost driving factors, a multivariable linear regression model was constructed. Table 5 lists the variables included in the final model together with their corresponding regression coefficients. Staphylococcus aureus, high PSI score (classes IV and V), and Streptococcus pneumoniae were all independent cost driving factors, increasing total costs of hospitalisation by $98 \%$, $43 \%$, and $18 \%$ respectively. Coxiella burnetii decreased total costs of hospitalisation by $35 \%$.

\section{Discussion}

In the past years, many studies have been conducted aiming at finding new strategies to lower incidence and improve clinical outcomes of CAP. To determine costeffectiveness of these strategies, knowledge about causing microorganisms, clinical outcomes, and related costs is needed. To our knowledge, this is the first study that studies the potential associations between costs of hospitalisation for CAP and its microbial aetiology. The main finding in the present study is that costs related to hospitalisation for CAP show great variation between patients, and CAP caused by S. pneumoniae and Staphylococcus aureus is associated with significantly higher costs, mainly due to longer duration of hospital stay.

In this study, S. pneumoniae was confirmed as the most prevalent causative pathogen in CAP (24.6\%). Compared to other aetiological groups, median LOS (8.5 days), rate of ICU admission (8\%), and one-year mortality (9.7\%) were relatively higher for pneumonia caused by $S$. pneumoniae, despite the relative younger age of patients of this aetiological group $(60.4 \pm 19.0$ years versus $64.4 \pm 17.6$ years, $\mathrm{p}: 0.033)$. These findings are in accordance with other CAP studies that also reported higher disease severity and 
Table 5 Multivariable linear regression model to predict total costs of hospitalisation in 361 patients with community-acquired pneumonia

\begin{tabular}{|c|c|c|c|c|c|c|}
\hline \multirow[b]{2}{*}{ Independent variables } & \multicolumn{3}{|c|}{ Crude analysis } & \multicolumn{3}{|c|}{ Multivariable analysis } \\
\hline & B & SE & p-value & B & SE & $\mathrm{p}$-value \\
\hline CONSTANT & & & & 3.558 & 0.023 & $<0.001$ \\
\hline Male gender & 0.009 & 0.032 & 0.77 & & & \\
\hline Chronic obstructive pulmonary disease & 0.009 & 0.044 & 0.83 & & & \\
\hline Congestive heart failure & 0.083 & 0.045 & 0.06 & & & \\
\hline Chronic renal disease & 0.077 & 0.057 & 0.17 & & & \\
\hline Diabetes mellitus & 0.047 & 0.045 & 0.30 & & & \\
\hline Pneumonia Severity Index classes IV-V & 0.176 & 0.030 & $<0.001$ & 0.158 & 0.030 & $<0.001$ \\
\hline Hospital 'Gelderse Vallei' & -0.063 & 0.042 & 0.13 & & & \\
\hline \multicolumn{7}{|l|}{ Pathogens: } \\
\hline Streptococcus pneumoniae & 0.070 & 0.038 & 0.07 & 0.067 & 0.036 & 0.07 \\
\hline Coxiella burnetii & -0.198 & 0.058 & 0.001 & -0.129 & 0.056 & 0.02 \\
\hline Haemophilus influenzae & -0.047 & 0.087 & 0.59 & & & \\
\hline Legionella pneumophila & 0.060 & 0.076 & 0.43 & & & \\
\hline Chlamydophila species & 0.087 & 0.076 & 0.25 & & & \\
\hline Mycoplasma pneumoniae & -0.179 & 0.134 & 0.18 & & & \\
\hline Staphylococcus aureus & 0.358 & 0.148 & 0.02 & 0.362 & 0.140 & 0.01 \\
\hline Viral pathogen & -0.046 & 0.064 & 0.48 & & & \\
\hline Other pathogen & 0.163 & 0.073 & 0.03 & 0.131 & 0.070 & 0.06 \\
\hline No pathogen found & -0.034 & 0.031 & 0.28 & & & \\
\hline
\end{tabular}

Prices are log-transformed and stated in euro.

Abbreviations: $B$ beta coefficient, $S E$ standard error

Bold numbers are included in the final model $(p<0.10)$.

increased need for ICU admission in S. pneumoniae pneumonia $[20,21]$. In agreement with these findings, we showed $S$. pneumoniae to be an independent costdriving factor (on average plus 18\% per hospitalisation).

Interestingly, Staphylococcus aureus could also be identified as an independent cost driving factor. CAPs caused by this pathogen were associated with a longer LOS and a higher mortality rate as well. This unfavourable outcome might be explained by the difficulty of treating Staphylococcus aureus pulmonary and systemic infections. Recently, Restrepo et al. have reported that late ICU admission versus early ICU admission is more prevalent in cases of CAP caused by Staphylococcus aureus, which aligns with the higher mortality rate observed in our study [22].

In our study, median total costs of hospitalisation were almost $€ 4,000$ per patient. These expenditures are higher compared to similar studies performed in Germany and Spain (median costs of $€ 1,362$ [23], €1,683 [24] and $€ 1,553$ [25], respectively), but lower than reported in a study from the United Kingdom ( $£ 1,700-5,100$, depending on length of stay [7]) and a European study (US\$6,530 in a secondary-level hospital in the Netherlands and US\$8,444 in a teaching hospital) [26]. The most likely explanation for these discrepancies in hospital costs are expected to be differences in registration, and individual resource item prices. Furthermore, diagnostic and treatment standards might differ between countries, leading to other price calculations. The recent study of Ostermann et al., however, showed no large differences in mean total duration of hospital stay for CAP between several EU countries (range 9.6-15.0 days) [26]. Unfortunately, most published studies do not indicate prices of individual resource items, which makes detailed comparisons between studies very difficult. Besides this, none of the available studies in literature included aetiological groups in their analyses, further limiting the possibility of a relative comparison with our study findings at this moment.

A further relevant finding in our study was that 57\% of the total costs of hospitalisation is due to general ward nursing. This finding is in accordance with other costs studies $[27,28]$. The latter is also reflected by $C$. burnetii, causing a relatively milder course of the disease and a significant shorter duration of hospital stay, being identified as an independent cost limiting factor in the multivariable model.

In the present study, costs of medication represented a very small part of the total costs of hospitalisation (on 
average 3.2\%). This means that policies aiming at an early intravenous to oral switch of antimicrobial treatment will not result in substantial cost-savings by reducing drugexpenses; costs might be reduced if the switch resulted in earlier hospital discharge. Medication costs for pneumonia caused by Legionella pneumophila appeared significantly higher compared to other aetiological groups. This is most likely caused by a higher ICU admission rate for these pneumonias and linked to the use of specific drugs such as fresh frozen plasma and sedatives.

This study has several strengths. First, we were able to identify the causative pathogen in a large number of patients enabling comparisons between aetiological groups. Second, we analysed resource utilization on an individual patient level. Third, data of two hospitals were studied (showing no differences) adding to the external validity of the findings. Besides this, the characteristics of the patients studied resemble data from another large nationwide CAP cohort from the Netherlands further adding to the generalisability of the findings [15].

There are also limitations that need to be addressed. First, due to missing data in some resources categories, not all 505 patients could be included in the overall cost analyses. This was due to being unable to retrieve some resource use from the years 2004 until 2006. We consider, however, that this has no impact on the validity of the findings because the more recent years are fully included, making the total costs of hospitalisation representative for the present standard of care for CAP. A further reassuring factor is that the comparison of patient characteristics and clinical outcomes of the 361 patients included in the analyses with the 144 patients not included, showed no large differences (see Additional file 1: Table S2). However, the lower number of patients available for analysis resulted in some aetiological subgroups becoming rather small.

Another limitation is that patients directly admitted to the ICU were absent in the study cohorts used. In the most recent cohort, 25 of the 817 eligible patients (3\%) were not included due to direct ICU admission. This phenomenon could have lead to an underestimation of the absolute costs of hospitalisation for CAP. However, given this low percentage, we expect this effect to be rather small. Furthermore, it is very unlikely to have biased the relative costs per pathogen.

Finally, we cannot rule out that the costs related to microbiology exams are overestimated (9\% share of total costs of hospitalisation). We studied patients who had participated in clinical studies in which a large panel of microbiological tests had been performed to maximize pathogen identification. However, presuming this resulted in a 50\% increase in microbiology costs, decreasing these costs by $50 \%$ influences the total costs by less than $5 \%$. In the present study, $58.2 \%$ of the causative pathogens could be identified, which is relatively high as compared to other studies [9].

\section{Conclusions}

In conclusion, in the present study we have shown that the total costs of hospitalisation for CAP vary considerably between patients and this variation can be largely explained by differences in length of hospital stay. Increased disease severity, and S. pneumoniae and Staphylococcus aureus as causative pathogens, are independent cost driving factors. This suggests, from a cost perspective, to focus further research on better in-hospital treatment and prevention of CAP caused by these pathogens. As standards of care and individual resource item prices are expected to differ between countries, further study in other countries should be performed to confirm the results of this study.

\section{Consent}

From all patients written informed consent was obtained in both studies.

\section{Additional file}

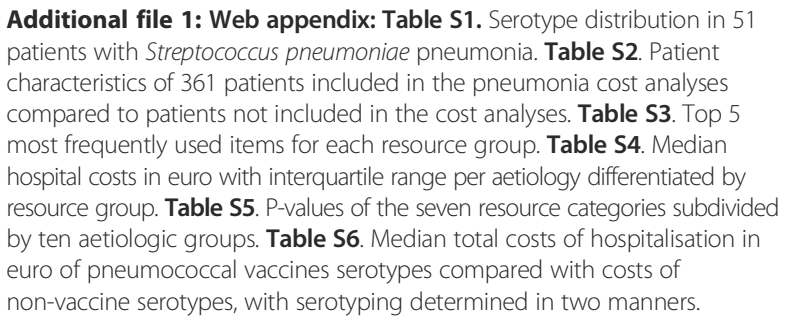

\section{Abbreviations}

C. burnetii: Coxiella burnetii; CAP: Community-acquired pneumonia; $H$. influenzae: Haemophilus influenzae; ICU: Intensive care unit; IQR: Interquartile range; L. pneumophila: Legionella pneumophila; M. pneumoniae: Mycoplasma pneumoniae; PCR: Polymerase chain reaction; PSI: Pneumonia severity index; S. pneumoniae: Streptococcus pneumoniae; SD: Standard deviation.

\section{Competing interests}

The department of Pharmacoepidemiology and Clinical Pharmacology, Utrecht Institute for Pharmaceutical Sciences, has received unrestricted research funding from the Netherlands Organisation for Health Research and Development (ZonMW), the Dutch Health Care Insurance Board (CVZ), the Royal Dutch Pharmacists Association (KNMP), the private-public funded Top Institute Pharma (www.tipharma.nl, includes co-funding from universities, government, and industry), the EU Innovative Medicines Initiative (IMI), EU 7th Framework Program (FP7), the Dutch Medicines Evaluation Board, the Dutch Ministry of Health and industry (including GlaxoSmithKline, Pfizer, and others).

\section{Authors' contributions}

SMCS performed the data analysis and interpretation and drafted the manuscript. WJWB and GTR were involved in data interpretation and revised the manuscript critically for important intellectual content. RH, GPV and JCG revised the manuscript critically. EMWG designed the study, was involved in data analysis and interpretation and revised the manuscript critically for important intellectual content. All authors had full access to the data and can take responsibility for the integrity of the data and the accuracy of the data analysis. All authors approved the final version of the manuscript. EMWG is the guarantor. All authors read and approved the final manuscript. 


\section{Acknowledgements}

We are indebted to Mark Ruitenbeek, Mariette Broekman, and Saskia Linssen (Department of Finances and Information services, St. Antonius Hospital, Nieuwegein) for extracting resource data from the St. Antonius hospital administrative databases. We are also grateful to Rik Eding (Datawarehouse, Gelderse Vallei, Ede) for extracting resource data from the Gelderse Vallei administrative databases and to Mirian Kaal (Department of Hospital Pharmacy, Gelderse Vallei, Ede), who helped us to complete patient's medication records.

\section{Funding}

This study was financially supported by GlaxoSmithKline.

\section{Author details}

'Department of Internal Medicine, St Antonius Hospital, P.O. Box 2500, 3430 EM, Nieuwegein, The Netherlands. ${ }^{2}$ Department of Internal Medicine, Gelderse Vallei Hospital, P.O. Box 9025, 6710 HN, Ede, The Netherlands. ${ }^{3}$ Department of Medical Microbiology and Immunology, St Antonius Hospital, P.O. Box 2500, 3430 EM, Nieuwegein, The Netherlands. ${ }^{4}$ Department of Pulmonology, St Antonius Hospital, P.O. Box 2500, 3430 EM, Nieuwegein, The Netherlands. ${ }^{5}$ Department of Pulmonology, University Medical Centre Utrecht, P.O. Box 85500, 3508 GA, Utrecht, The Netherlands. ${ }^{6}$ Department of Sciences, Roosevelt Academy, P.O. Box 94, 4330 AB, Middelburg, The Netherlands. ${ }^{7}$ Division of Pharmacoepidemiology and Clinical Pharmacology, University of Utrecht, P.O. Box 80125, 3508 TC, Utrecht, The Netherlands. ${ }^{8}$ Department of Clinical Pharmacy, St Antonius Hospital, P.O. Box 2500, 3430 EM, Nieuwegein, The Netherlands.

\section{Received: 18 March 2014 Accepted: 10 June 2014}

Published: 17 June 2014

\section{References}

1. Anderson RN: Deaths: leading causes for 2000. Natl Vital Stat Rep 2002, 50(16):1-85

2. Thomas CP, Ryan M, Chapman JD, Stason WB, Tompkins CP, Suaya JA, Polsky D, Mannino DM, Shepard DS: Incidence and Cost of Pneumonia in Medicare Beneficiaries. Chest 2012, 142(4):973-981.

3. Fry AM, Shay DK, Holman RC, Curns AT, Anderson L: Trends in hospitalizations for pneumonia among persons aged 65 years or older in the United States, 1988-2002. JAMA 2005, 294(21):2712-2719.

4. Jackson ML, Neuzil KM, Thompson WW, Shay DK, Yu O, Hanson CA, Jackson LA: The burden of community-acquired pneumonia in seniors: results of a population-based study. Clin Infect Dis 2004, 39(11):1642-1650.

5. Bauer TT, Welte T, Ernen C, Schlosser BM, Thate-Waschke I, De Zeeuw J, Schultze-Werninghaus $\mathrm{G}$ : Cost analyses of community-acquired pneumonia from the hospital perspective. Chest 2005, 128(4):2238-2246.

6. Monge V, San-Martin VM, Gonzalez A: The burden of community-acquired pneumonia in Spain. Eur J Public Health 2001, 11(4):362-364.

7. Guest JF, Morris A: Community-acquired pneumonia: the annual cost to the National Health Service in the UK. Eur Respir J 1997, 10(7):1530-1534.

8. Martin LG, Freedman VA, Schoeni RF, Andreski PM: Health and functioning among baby boomers approaching 60. J Gerontol B Psychol Sci Soc Sci 2009, 64(3):369-377.

9. Tessmer A, Welte T, Schmidt-Ott R, Eberle S, Barten G, Suttorp N, Schaberg T, CAPNETZ study group: Influenza vaccination is associated with reduced severity of community-acquired pneumonia. Eur Respir $J 2011$ 38(1):147-153.

10. Meijvis SC, Hardeman H, Remmelts HH, Heijligenberg R, Rijkers GT, Van Velzen-Blad H, Voorn GP, van de Garde EM, Endeman H, Grutters JC, Bos WJ, Biesma DH: Dexamethasone and length of hospital stay in patients with community-acquired pneumonia: a randomised, double-blind, placebo-controlled trial. Lancet 2011, 377(9782):2023-2030.

11. Maruyama T, Taguchi O, Niederman MS, Morser J, Kobayashi H, Kobayashi T, D'Alessandro-Gabazza C, Nakayama S, Nishikubo K, Noguchi T, Takei Y, Gabazza EC: Efficacy of 23-valent pneumococcal vaccine in preventing pneumonia and improving survival in nursing home residents: double blind, randomised and placebo controlled trial. BMJ 2010, 340:c1004

12. Snedecor SJ, Strutton DR, Ciuryla V, Schwartz EJ, Botteman MF: Transmission-dynamic model to capture the indirect effects of infant vaccination with Prevnar (7-valent pneumococcal conjugate vaccine (PCV7)) in older populations. Vaccine 2009, 27(34):4694-4703.
13. Huss A, Scott P, Stuck AE, Trotter C, Egger M: Efficacy of pneumococcal vaccination in adults: a meta-analysis. CMAJ 2009, 180(1):48-58.

14. Moberley SA, Holden J, Tatham DP, Andrews RM: Vaccines for preventing pneumococcal infection in adults. Cochrane Database Syst Rev 2008, 1 : CD000422. doi(1):CD000422.

15. Remmelts HH, Spoorenberg SM, Oosterheert JJ, Bos WJ, De Groot MC, Van de Garde EM: The role of vitamin D supplementation in the risk of developing pneumonia: three independent case-control studies. Thorax 2013, 68(11):990-996.

16. Endeman $\mathrm{H}$, Meijvis SC, Rijkers GT, Van Velzen-Blad H, Van Moorsel $\mathrm{CH}_{\text {, }}$ Grutters JC, Biesma DH: Systemic cytokine response in patients with community-acquired pneumonia. Eur Respir J 2011, 37(6):1431-1438.

17. Van Mens SP, Meijvis SC, Endeman H, Van Velzen-Blad H, Biesma DH, Grutters JC, Vlaminckx BJ, Rijkers GT: Longitudinal analysis of pneumococcal antibodies during community-acquired pneumonia reveals a much higher involvement of Streptococcus pneumoniae than estimated by conventional methods alone. Clin Vaccine Immunol 2011, 18(5):796-801.

18. DBC Onderhoud Price Table V20120329. [http://www.dbconderhoud.nl/ index.php?option=com_docman\&task=cat_view\&gid=725\&ltemid=404]

19. Medicine costs Health Care Institute the Netherlands. [http://www. medicijnkosten.nl/]

20. Capelastegui A, Espana PP, Bilbao A, Gamazo J, Medel F, Salgado J, Gorostiaga I, De Goicoechea MJ L, Gorordo I, Esteban C, Altube L, Quintana $\mathrm{JM}$, on behalf of Poblational Study of Pneumonia (PSoP) Group: Etiology of community-acquired pneumonia in a population-based study: Link between etiology and patients characteristics, process-of-care, clinical evolution and outcomes. BMC Infect Dis 2012, 12(1):134.

21. Restrepo MI, Mortensen EM, Velez JA, Frei C, Anzueto A: A comparative study of community-acquired pneumonia patients admitted to the ward and the ICU. Chest 2008, 133(3):610-617.

22. Restrepo MI, Mortensen EM, Rello J, Brody J, Anzueto A: Late admission to the ICU in patients with community-acquired pneumonia is associated with higher mortality. Chest 2010, 137(3):552-557.

23. Ott SR, Hauptmeier BM, Ernen C, Lepper PM, Nuesch E, Pletz MW, Hecht J, Welte T, Bauer TT: Treatment failure in pneumonia: impact of antibiotic treatment and cost analysis. Eur Respir J 2012, 39(3):611-618.

24. Reyes S, Martinez R, Valles JM, Cases E, Menendez R: Determinants of hospital costs in community-acquired pneumonia. Eur Respir J 2008, 31(5):1061-1067.

25. Bartolome M, Almirall J, Morera J, Pera G, Ortun V, Bassa J, Bolibar I, Balanzo $X$, Verdaguer A: Maresme Community-Acquired Pneumonia Study Group (GEMPAC): A population-based study of the costs of care for community-acquired pneumonia. Eur Respir J 2004, 23(4):610-616.

26. Ostermann H, Garau J, Medina J, Pascual E, McBride K, Blasi F, REACH study group: Resource use by patients hospitalized with community-acquired pneumonia in Europe: analysis of the REACH study. BMC Pulm Med 2014 14(1):36-2466.

27. Sun HK, Nicolau DP, Kuti JL: Resource utilization of adults admitted to a large urban hospital with community-acquired pneumonia caused by Streptococcus pneumoniae. Chest 2006, 130(3):807-814.

28. Orrick JJ, Segal R, Johns TE, Russell W, Wang F, Yin DD: Resource use and cost of care for patients hospitalised with community acquired pneumonia: impact of adherence to infectious diseases society of america guidelines. Pharmacoeconomics 2004, 22(11):751-757.

\section{doi:10.1186/1471-2334-14-335}

Cite this article as: Spoorenberg et al:: Microbial aetiology, outcomes, and costs of hospitalisation for community-acquired pneumonia; an observational analysis. BMC Infectious Diseases 2014 14:335. 